\title{
Epigenetic influences on the developing brain: effects of hormones and nutrition
}

This article was published in the following Dove Press journal:

Advances in Genomics and Genetics

8 May 2015

Number of times this article has been viewed

\author{
Bridget $M$ Nugent ${ }^{\prime}$ \\ Margaret M McCarthy ${ }^{2}$ \\ 'Department of Animal Biology, \\ School of Veterinary Medicine, \\ University of Pennsylvania, \\ Philadelphia, PA, USA; ${ }^{2}$ Department \\ of Pharmacology, University of \\ Maryland School of Medicine, \\ Baltimore, MD, USA
}

\begin{abstract}
The developing brain is subject to modifying influences, both in utero and early postnatally. Some of these are intrinsic, such as gonadal steroids, while others are externally imposed, such as maternal nutrition or stress. All of these variables can have enduring consequences by imposing epigenetic modifications on the genome that alter set points for activation in adulthood, thereby reflecting early-life programming. In this review, we provide an overview of the most well studied epigenetic processes that occur in the brain. Next, we summarize the studies to date that have implicated gonadal steroids, stress exposure, and nutritional deficits/ excess in changes in neural epigenetic marks, which ultimately alter brain development, but we also note that this field is still in its infancy. Epigenetic regulators include DNA methylation, changes to the chromatin via acetylation and other chemical modifiers, and noncoding RNAs all of which impact the expression of specific genes. In this way gonadal steroids in the developing male fetus direct masculinization of adult brain and behavior, and similarly in utero exposure to a high-fat or calorie-restricted diet impacts glucose metabolism and body fat composition throughout life. Stress early in life changes the sensitivity of the hypothalamicpituitary-adrenal (HPA) axis to subsequent stressors and this too is mediated, at least in part, by epigenetic changes to key genes to alter the responsiveness threshold. Epigenetics is the integration of the environment and the genome, and hormones and nutrition provide the bridge that allows that integration to occur.
\end{abstract}

Keywords: epigenetics, early-life programming, brain development, hormones, nutrition

\section{Introduction}

Normal development of the central nervous system requires intricately orchestrated processes to seamlessly align, enabling proper patterning of cell types, cell-to-cell interactions, subregion development, and inter- and intraregion wiring to occur. Temporal and spatial control of gene expression and repression within the developing brain enables this remarkable complexity. A number of factors determine gene expression patterns during brain development, most notably genetic makeup, environmental influences, and epigenetic processes, which form a bridge between genes and the environment. Epigenetic modifications as important regulators of gene expression is not a new idea, as it dates back to Waddington in $1942,{ }^{1}$ but there has been a renaissance in the field of neuroscience where rapidly occurring changes to DNA and chromatin are emerging as key regulators of neural plasticity as well as enduring changes to brain and behavior. Neuroscience has also embraced the notion of early-life programming in response to environmental stimuli as a major determinant of adult health and disease. The set point of multiple homeostatic mechanisms is determined developmentally, and the
Correspondence: Bridget M Nugent

Department of Animal Biology, School of Veterinary Medicine, University of Pennsylvania, Hill Pavilion, 380 South University Avenue, Room 437, Philadelphia, PA 19104, USA

Tel + I 2158981368

Fax +l 2155735187

Email bnugent@vet.upenn.edu 
maintenance of these set points appears to involve epigenetic modifications which in turn are responsive to environmental and physiological influences.

\section{A primer on epigenetic mechanisms}

The term "epigenetics" broadly refers to several cellular processes that permanently or transiently alter gene expression in response to exogenous cues. These processes include DNA methylation, histone modifications, and mRNA editing and degradation by noncoding RNAs. They are closely entwined, often working together to achieve changes in chromatin structure and ultimately gene expression.

\section{DNA methylation}

Research on arguably the most well studied epigenetic process, DNA methylation, has traditionally focused on cytosine-guanine dinucleotide $(\mathrm{CpG})$ methylation within a gene's promoter region, although DNA methyltransferase (DNMT) enzymes can covalently link methyl groups to cytosine residues outside of $\mathrm{CpG} \operatorname{sites}^{2,3}$ and throughout the genome. ${ }^{4}$ Genome-wide DNA methylation analysis has revealed that most $\mathrm{CpG}$ sites outside of regulatory regions are highly methylated, whereas methylation levels are comparatively lower in gene promoter and enhancer regions. DNA methylation has traditionally been associated with transcriptional repression, ${ }^{5}$ and most research on DNA methylation continues to support its role in gene silencing. DNA methylation must occur at particular loci in the genome to be effective at transcriptional silencing, most likely in regions critical for transcription factor (TF) binding and loci where histone modifications interact with DNA modifications to chemically lock chromatin. Studies have shown that methylation at most TF binding sites can repress transcription; while at other sites methylation seems to have no effect on TF binding capability. ${ }^{6,7}$

By contrast, levels of DNA methylation in a gene's promoter, often, do not linearly relate to mRNA expression. ${ }^{8,9}$ Changes in DNA methylation in response to various stimuli can be detected in transcriptional regulatory regions and have no apparent correlation with gene expression, but instead may reflect past patterns of gene expression and are thus "vestigial" methylated regions. ${ }^{10}$ Alternatively, promoter methylation may be more relevant to directing specific promoter use or even splice variants (Figure 1). ${ }^{11,12}$

Several DNMT enzyme isoforms work together to establish and maintain DNA methylation patterns in the mammalian genome. De novo methylation is mainly implemented by DNMT3a and DNMT3b, which are critical for
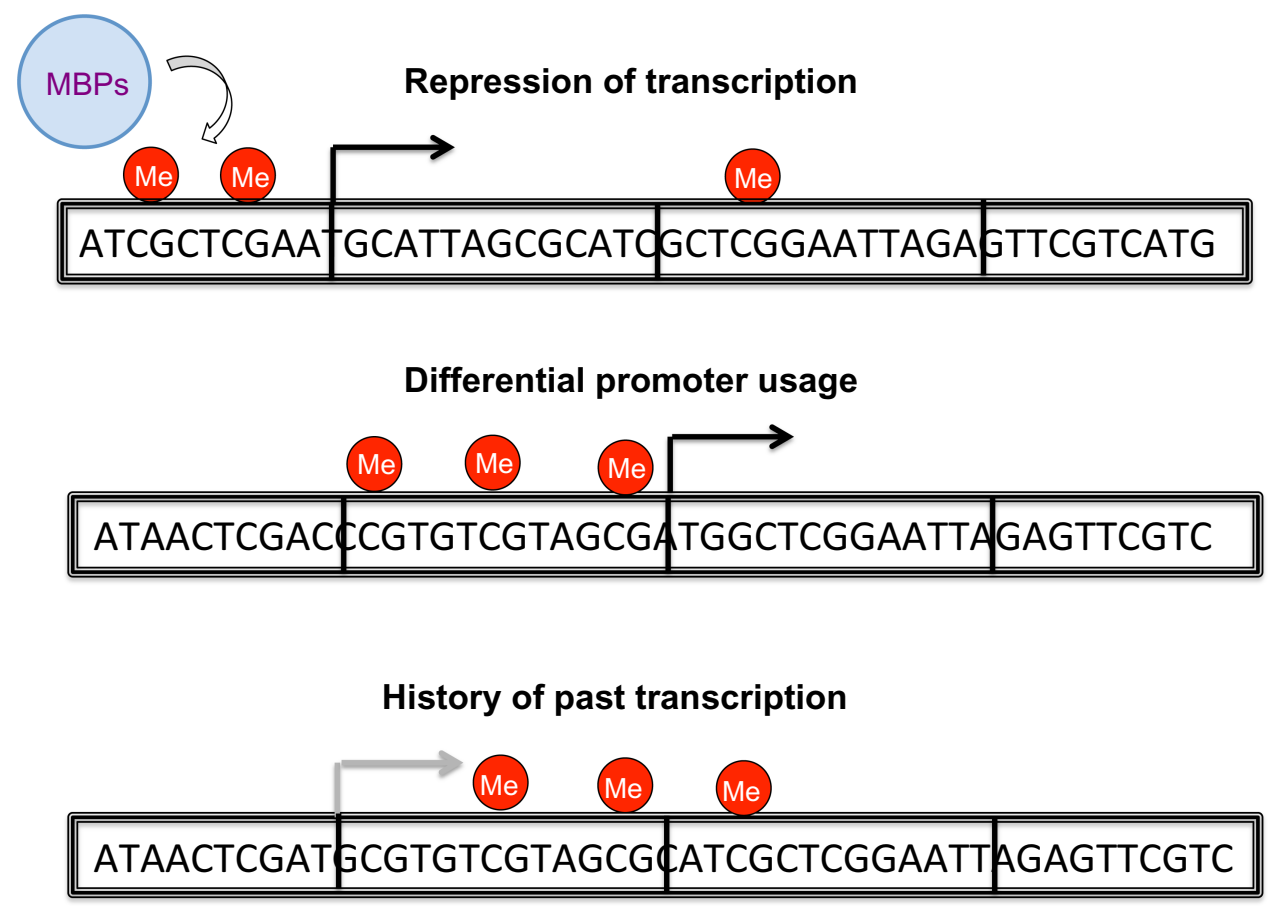

Figure I DNA methylation and gene expression.

Notes: The canonical view of DNA methylation at CPG sites involves recruitment of methyl binding proteins (MBP) and repression of transcription by preventing the formation of the transcriptional complex. It is now becoming apparent that methylation can also direct promoter usage and hence isoform expression without an overall change in gene expression. Additional evidence suggests some genes are methylated after they have been heavily expressed and thus mapping of CpG's may reflect past history more than future gene expression potential. 
normal embryonic development. ${ }^{13}$ Another member of the DNMT3 family, DNMT3L does not possess methyltransferase capabilities but can enhance the activity of DNMT3a and DNMT3b, stimulating and, perhaps, spatially directing de novo methylation during early development. ${ }^{14}$ DNMT1 has traditionally been considered the "maintenance" methyltransferase, responsible for reproducing DNA methylation patterns established by the DNMT3 isoforms on hemimethylated DNA following replication and repair. This overly simplistic view of the roles of the DNMTs has been refined by several recent findings. ${ }^{15}$ We now know that DNMT1 collaborates with DNMT3a and DNMT3b to establish de novo methylation patterns during development. ${ }^{16,17}$ Likewise, DNMT3a and DNMT3b also appear necessary for maintenance of DNA methylation patterns. ${ }^{18-20}$ DNMT2 was perhaps poorly named, because it does not possess DNMT activity, ${ }^{21}$ but is instead a tRNA methyltransferase..$^{22}$ Transcriptional regulation is independent of DNA methylation in organisms that express DNMT2 but lack the other DNMT isoforms, such as Drosophila melanogaster. ${ }^{23}$

Years ago, DNA methylation was considered a permanent modification, as demethylation was thought to only occur passively as a consequence of failure to maintain methylation patterns following cell division. This view led many to believe that once established, DNA methylation patterns in the brain were constant, since cell genesis and differentiation were considered rare outside of development. However we now appreciate the dynamic nature of DNA methylation and active demethylation, particularly in the brain. ${ }^{24}$ This new appreciation was facilitated by the discovery of the ten-eleven translocation (TET) proteins, which oxidize 5-methylcytosine $(5 \mathrm{mC})$ to 5 -hydroxymethylcytosine (5hmC), 5-formylcytosine (5fC), and 5-carboxylcytosine $(5 \mathrm{caC})$, thereby creating targets for excision by DNA glycosylases. ${ }^{25}$ Dynamism in DNA methylation is imperative during early embryonic development, ${ }^{26}$ and demethylation plays a large role in tissue-specific differentiation. ${ }^{27}$

\section{Histone modifications}

Equally important for controlling gene expression are histone modifications, which are both dependent on and determine DNA methylation patterns. Histones are comprised of two copies of four core histone proteins, known as H2A, H2B, $\mathrm{H} 3$, and H4. DNA wound around this histone core forms the basic unit of chromatin, the nucleosome. Histones are subject to dynamic posttranslational modifications on the $\mathrm{N}$-terminal tails. Histone modifications affecting chromatin structure include acetylation, phosphorylation, methylation, biotinylation, ubiquitylation, and sumoylation. The aptly named "histone code", or the specific positioning and combination of post translational modifications made to the histones, determines whether a particular stretch of DNA is in a repressed or transcriptionally accessible state. ${ }^{28}$ Histone acetylation is a particularly well-studied modification in brain development. Chromatin is opened or tightened based on the activity of histone acetyltransferases (HATs) or histone deacetylases (HDACs), respectively, through addition or removal of acetyl groups from lysine residues on the N-termini of histone proteins. HATs and HDACs are recruited to specific sites on the chromatin by transcription factors, forming activator or repressive complexes. ${ }^{29-31}$ Pharmacological and genetic studies have demonstrated the importance of dynamism in histone acetylation patterns during brain development, revealing in particular the importance of histone acetylation in neural cell fate and neuronal maturation. $^{32-34}$

Histone methylation is another critical modification for brain development. Location and titration of methyl groups on a histone's tail determines whether methylation acts to stimulate or repress transcription. Trimethylation of lysine 27 on histone $\mathrm{H} 3$ (H3K27me3) is known to be associated with transcriptional restriction at specific promoters, and is a key player in X-inactivation. ${ }^{35}$ During forebrain development, retinoic acid signaling induces a pattern of $\mathrm{H} 3 \mathrm{~K} 27 \mathrm{me} 3$ that initiates a neurogenic program in neural stem cells. ${ }^{36}$ Trimethylation at lysine $9(\mathrm{H} 3 \mathrm{~K} 9 \mathrm{me} 3)$ is also a transcription silencing modification. Genetic deletion of demethylases that act at both $\mathrm{H} 3 \mathrm{~K} 27 \mathrm{me} 3$ and $\mathrm{H} 3 \mathrm{~K} 9 \mathrm{me} 3$ results in severe developmental defects in the brain. ${ }^{37}$

\section{Noncoding RNAs}

Only a small fraction of the mammalian genome is devoted to producing protein-coding messenger RNA (mRNA), however $70 \%-90 \%$ of the genome is transcribed during development and thereafter, producing a huge library of noncoding RNAs, ${ }^{38}$ which are emerging as key players in epigenetic control of gene expression. MicroRNAs (miRNAs) are among the best studied noncoding RNAs involved in brain development. miRNAs are 19-23 bases long but cleaved from longer noncoding precursor RNAs known as primary miRNAs (pri-miRNAs), which are typically transcribed by RNA polymerase II. ${ }^{39}$ While still inside the nucleus primiRNA hairpins are preprocessed by the enzyme Drosha (known as pre-miRNAs), ${ }^{40}$ then exported from the nucleus via the double-stranded RNA binding protein, Exportin-5. ${ }^{41}$ In the cytoplasm, pre-miRNAs are cleaved by the enzyme 
Dicer to produce mature miRNAs. ${ }^{42}$ In the mammalian brain, several hundred miRNAs are expressed at key time points during development ${ }^{43}$ and can cause downregulation of gene expression by interacting with partially complimentary mRNA sequences, resulting in mRNA degradation and/or translational interference. ${ }^{44}$ Single miRNAs can regulate hundreds of mRNAs, making these molecules potentially critical in controlling gene networks in the brain. miRNAs also appear to alter gene expression by interacting with other epigenetic processes, including directing DNA methylation, altering chromatin posttranslational modifications, and modulating translation in neuronal polyribosomes. ${ }^{43}$

Another class of noncoding RNA, long noncoding RNAs (lncRNAs), has also recently received attention for its role in neurodevelopment. ${ }^{45}$ lncRNAs are longer than 200 nucleotides, lack open reading frames, and are often polyadenylated. ${ }^{46,47}$ Like miRNAs, IncRNAs have the ability to interact with both complimentary nucleic acid sequences and proteins necessary for gene regulation, however lncRNAs also have the ability to fold into more complex and flexible secondary structures, providing greater diversity in both nucleic acid and protein sequence recognition and enables them to act as tethers between proteins. ${ }^{48,49}$ Remarkably, large-scale RNA sequencing studies have revealed that lncRNA expression patterns exhibit greater cell-type specificity than protein-coding RNAs. ${ }^{50,51}$ Different lncRNAs are expressed at different stages of development and are likely key players determining cell fate. ${ }^{46,47}$ In the nucleus, the function of IncRNAs is to direct DNA methylation and histone modifications to specific locations on the chromatin, typically resulting in restricted gene expression. ${ }^{52-54}$ lncRNAs can also contribute to activating the expression of specific genes by promoting histone modifications and stimulating enhancer regions to open chromatin structure..$^{55-57}$

\section{Genomic imprinting in the brain}

Epigenetic processes contributing to brain development take action as early as conception. Diploid offspring receive one copy, or allele, of every autosomal gene from each parent. The majority of alleles are equally expressed, however, in some cases duplicate alleles are silenced based on their parental lineage. Known as imprinted genes, the expression of these alleles is determined by their inheritance from either the parental sperm or egg genome. Imprinted genes are disproportionally active in the brain compared to other somatic tissues, suggesting their critical role in brain development and function. ${ }^{58}$ Imprinted genomic regions have been shown to code for IncRNAs, which then act to silence imprinted regions through binding to complimentary sequences. ${ }^{59}$
Early research on imprinted genes by Keverne et $\mathrm{al}^{60}$ found that these genes are critical regulators of brain size, suggesting the presence of imprinted genes in the brain is likely necessary for neurodevelopmental processes. Genes that are maternal in origin tend to favor brain growth while paternal alleles do the opposite and limit brain growth. ${ }^{61,62}$ Moreover, cells expressing imprinted genes from a given lineage spatially localize to different regions of the developing brain. ${ }^{60}$ Several studies have shown expression of imprinted genes can be cell-type specific, ${ }^{63-65}$ further increasing the variety and impact of epigenetic regulation via imprinting.

\section{Early-life programming Steroid hormones}

Steroid hormones are powerful regulators of gene expression via their activation of a superfamily of nuclear transcription factors. Classically, steroid receptors recognize and bind to palindromic hormone response elements (HREs) coded in the promoter regions of target genes, but the impact of steroids is expanded by their association with large numbers of transcriptional activators and repressors. Included among these are several molecules with HAT activity, thereby increasing access to the DNA, and it was this feature that made them a natural candidate for consideration when evaluating potential epigenetic effects. Steroid receptors also exist in the membrane where they interact with a variety of kinases, G-protein coupled receptors (GPCRs), and ionic receptors to induce rapid signaling. Because of the direct and indirect association of steroids and their cognate receptors with DNA, there was sound reason to consider them in the context of enduring epigenetic effects (Reviewed in Nugent and McCarthy ${ }^{66}$ ).

Steroids relevant to the developing brain can be divided into those derived from the gonad and major determinants of sex differences in the brain, versus those derived from the adrenal and induced in response to stress. The prenatal period includes a mix of fetal and maternally derived steroids, with the former differing in males versus females, while maternal steroids impact both sexes equally. The placenta is an additional source of steroids that reach the developing fetus. Direct influence of the placenta ends at birth, but evidence for enduring imprints on the brain is emerging.

\section{Gonadal steroids establish enduring sex differences in the brain via epigenetic mechanisms}

Sexual differentiation of the brain is an active process that occurs early in development as a result of higher levels of gonadal steroids in males compared to females, followed by 
a latent period during which steroids are low to undetectable in both sexes (ie, the juvenile period), and then a reawakening by the steroids produced at puberty. The behavioral and physiological endpoints associated with the reawakening are determined by the earlier differentiation, including an enduring pattern of dendritic spine density on preoptic area (POA) neurons, ${ }^{67,68}$ the morphology of astrocytes in the arcuate, and the dendritic branching frequency in the ventromedial nucleus of the hypothalamus. ${ }^{69}$ The memory of this earlier differentiation is assumed to be, at least in part, the result of epigenetic changes to the genome of neurons and glia. In mammals, sex determination begins with the sry gene on the Y chromosome directing the differentiation of the bipotential gonad toward a testicular phenotype. In the absence of the sry gene, such as in an XX individual, the bipotential gonad differentiates into an ovary. Steroids and other factors produced by the testis versus the ovary will then direct the differentiation and organization of the reproductive tract and secondary sex characteristics. One of the steroid responsive target tissues is the brain, which becomes masculinized or feminized during a restricted sensitive window of development. Similar to the gonads, the brain is organized along a male phenotype by androgens produced by the testis in males, whereas in the absence of gonadal steroids (as in the ovary, which is quiescent early in development), the brain will be organized along a female phenotype. In the rodent, this process is initiated by a surge of androgen production from the fetal testis toward the end of pregnancy and enduring into the 1st day or so following birth. In primates, including humans, sexual differentiation of the brain occurs predominantly prenatally although circulating steroid levels are very high in newborn males (reviewed in Lenz et $\mathrm{al}^{70}$ ).

The consequences of a masculinized versus feminized brain becomes evident at puberty when behavior begins to diverge and is coordinated with reproductive status. Thus in our animal models, an animal with a masculinized brain will attempt to mount a receptive female, will be more aggressive, and will show higher anxiety levels than an animal with a feminized brain, regardless of the chromosomal sex or even the gonadal/reproductive tract sex. Feminized animals respond to mounts from a masculinized animal with a sexually receptive lordosis posture, provided they are in a physiologically receptive state. Sex differences in mating behavior and the associated brain regions are among the most robust, arguably because of the direct relevance to reproduction and therefore selective pressures.

An unsolved mystery regarding the establishment of sex differences in the brain has been the early time point at which steroids set the stage for adult responsiveness, what is often called the organizational/activational hypothesis of steroid action. ${ }^{71}$ How do the effects of the steroid exposure endure across the period of juvenile and adolescent development when there are little to no gonadal steroids produced? What is the source of the cellular "memory"? Many of the variables that are modified by steroids in the male brain were originally considered terminal, ie, cell death, synaptogenesis, axonal growth, and dendritic branching. Even the terminology used reflected permanency as researchers referred to the blueprint created by steroids to alter the neuronal architecture. But we now understand that new neurons can be born in the adult brain, synapses come and go, and so do their attendant axons and dendrites, even nonneuronal proliferative cells such as microglia are important contributors to normal brain function. ${ }^{72}$ Thus the mature brain is far more dynamic than previously realized. To our lab and several others, this suggested that there is an enduring memory that retains the masculine or feminine pattern of neuronal activity and the ideal source is steroid-induced epigenetic changes to the genome. ${ }^{73}$ There are two ways to ascertain whether epigenetics directs sexual differentiation of the brain. The first is to simply look for sex differences in epigenetic marks such as chromatin modifications or DNA methylation. The second is to block or induce epigenetic changes in one sex and see if it mimics the phenotype of the other sex. Both approaches have proven informative but also raise many unanswered questions.

Hyperacetylation is associated with gene expression, and male rat pups were found to have significantly higher H3K9/14ac levels in the hippocampus and cortex than females. ${ }^{74}$ Trimethylation at the same lysine residue on histone three (H3K9me3) is also associated with higher gene expression and it too was higher in males, but what genes were being expressed and the functional significance remains unclear. In contrast to $\mathrm{H} 3 \mathrm{~K} 9 \mathrm{me} 3, \mathrm{H} 3 \mathrm{~K} 4 \mathrm{me} 3$ (another histone modification associated with active transcription) was found to be higher in females in a related brain region, the principle nucleus of the stria terminalis $\left(\mathrm{pBNST}^{75}\right)$, and here the authors identified regulated genes by ChIP-Seq, resulting in far more robust and meaningful sex differences.

Using the second approach of identifying a sex difference in the brain and then determining if it is maintained epigenetically, Murray et $\mathrm{al}^{76}$ determined a role for $\mathrm{H} 3$ acetylation in the control of cell death in the pBNST. The POA is a diencephalic subnuclei important to mating and affiliative, particularly maternal behaviors, and estrogens play a central role in these behaviors. The enzyme aromatase is rate 
limiting to estradiol production, and both the gene coding for aromatase (Cyp19a) and the alpha isoform of the estrogen receptor $(E s r l)$ were found to have varying profiles of acetylation between the sexes and across ages, revealing a complex pattern of regulation. ${ }^{77}$ A similar level of complexity was found when the DNA methylation profile of $\mathrm{CpG}$ islands in the promoters of both estrogen receptors (Esr1 and $E s r 2$ ) and the progesterone receptor were examined by pyrosequencing in multiple brain areas and developmental time points. There were sex differences in the amount of CpG methylation, and methylation was regulated by steroids, but the pattern was not consistent over time, across brain regions or within the same sex, again suggesting a dynamic pattern that is not particularly predictive of gene expression. ${ }^{9}$ More recently there have been attempts to identify novel genes that are regulated epigenetically to induce and maintain sex differences in brain and behavior. Using Reduced Representation Bisulfite Sequencing (RRBS), Ghahramani et $\mathrm{al}^{78}$ examined the methylome in the BNST/POA and the septum of male and female rat pups and adults. They also examined the impact of treating neonatal females with a masculinizing dose of testosterone. Surprisingly they found neonatal hormonal modulation of DNA methylation did not manifest until the animals were adults, up to 60 days after the hormone exposure. This observation combined with the enduring but dynamic changes observed following gonadal steroid hormone treatment by other groups suggest we have much to learn regarding the relationship between hormonal signaling and epigenetic regulation.

In addition to histone modifications and DNA methylation, the newborn mouse brain displays many sex differences in miRNA expression, which are the result of a combination of chromosomal and hormonal differences. ${ }^{79}$ miRNAs are sensitive to hormonal modulation during the critical period for sexual differentiation of the brain, and blocking the conversion of testosterone to estradiol in neonatal male mice leads to female-like patterns of miRNA expression in the brain. ${ }^{80}$ The functional significance of these sex differences and hormonal modulation of miRNA remains to be determined but is an exciting area for future exploration.

\section{Early-life stress alters the epigenome to alter stress axis programming}

The ability of early-life stress to permanently reprogram the hypothalamic-pituitary-adrenal (HPA) axis is one of the most reliable examples of enduring physiological change from environmental influence during development. Earlylife stress can begin in utero by stress to the mother, or postnatally, which usually involves neglect or abuse by the mother. Francis et $\mathrm{l}^{81}$ have modeled the impact of negligent maternal care using naturally occurring variation in the behavior of female laboratory rats toward their pups. Pups that are reared by a negligent mother become negligent mothers themselves, and those reared by a highly attentive mother are themselves attentive mothers, regardless of their genetic relatedness to the female that raises them. The methylation status of the promoter regions of the glucocorticoid receptor (GR) as well as the estrogen receptor in key brain regions involved in both the stress axis and maternal behavior are impacted by the maternal care received, and this is believed to form the basis for the transgenerational inheritance of behavior. ${ }^{82,83}$ Methylation pattern changes in the promoter of the GR assessed in postmortem hippocampi of humans suggest similarities in the sensitivity of this system to earlylife trauma. ${ }^{84}$

In addition to trauma during childhood, early prenatal stress has also been shown to affect long-term outcomes of offspring through various epigenetic mechanisms. In mice, chronic variable stress during the 1 st week of gestation induces long-term alterations in DNA methylation and gene expression of corticotropin-releasing factor (CRF) and the GR in male offspring, resulting in altered stress responsivity, anhedonia, and dysmasculinization. ${ }^{85}$ This phenotype can be passed to the prenatally-stressed offspring (F2 generation) via the paternal lineage by altering miRNA content in sperm. ${ }^{80,86}$ The remarkable impact of stress across generations was also observed in the F1 and F2 offspring of mice exposed to olfactory fear condition, with acetophenone, prior to mating. The offspring of the fear-conditioned mice had reduced DNA methylation at the promoter for the acetophenone receptor, which was inherited through parental germ cells. ${ }^{87}$

\section{Nutrition}

In the early 1990s, Hales and Barker ${ }^{89}$ found epidemiological evidence that lead to coining of the "Barker Hypothesis" (also known as the Developmental Origins of Health and Disease [DOHaD] Hypothesis, and the Thrifty Phenotype Hypothesis) which links adult-onset chronic health conditions, including neurodegenerative disorders, to in utero development. ${ }^{88}$ Barker theorized that lack of suitable nutrition during early development alters an individual's developmental trajectory by preparing them for a lifetime of scarce nutritional resources and ultimately a shorter lifespan. ${ }^{89}$ Metabolic adaptations made during development in response to environmental cues affect the individual's physiological programming for life. A similar perspective has since been 
applied to developmental stress, and more recently to steroids of gonadal origin, all having the common theme of early-life programming impacting adult functioning via epigenetic modification (Figure 2).

Recent epigenetic studies support the Barker hypothesis' assertion that developmental defects in nutrition can lead to long-term health consequences for the developing individual, and also for their offspring. Obesity affects over one-third of the US adult population, ${ }^{90}$ and is linked to myriad health problems, a decreased quality of life, and premature death. Although lack of physical activity and overconsumption of calories undoubtedly contributes to overweight and obese phenotypes, research in animals and long-term studies in human populations has illustrated that maternal obesity during pregnancy can have long-term consequences on offspring metabolism and body composition, leading to chronic illnesses such as liver dysfunction and cardiovascular disease. ${ }^{91-95}$ Work from Dunn and Bale ${ }^{96}$ has shown that maternal high-fat diet can alter glucose homeostasis and body length across multiple generations, likely by altering methylation of genes necessary for growth hormone signaling. Three generations after exposure to maternal high-fat diet, female, but not male, offspring still had significantly altered body composition. The phenotype was shown to be passed through the paternal lineage by genetic imprinting, suggesting that environmental stimuli can be programmed into the genome and transmitted to future generations. ${ }^{97}$

Additional studies have found a link between DNA methylation and the perpetuation of obesity. Three generations of mice genetically predetermined for obesity were fed normal diets or mouse chow containing methyl supplements. While mice fed normal diets became progressively more obese across generations, mice fed diets inducing hypermethylation did not show transgenerational increases in obesity. ${ }^{98}$ Exposure to a high calorie diet in utero may program developing reward circuits in the brain, resulting in lower DNA methylation on the promoters of dopamine and opioid signaling genes, resulting in long-term changes in reward circuit gene expression and enhanced preference for palatable foods. ${ }^{99}$

Caloric restriction as a result of famine, poor nutrition, or maternal dieting can also have long-term effects on developing offspring. A moderate (30\%) reduction in caloric intake during pregnancy was shown to have marked effects

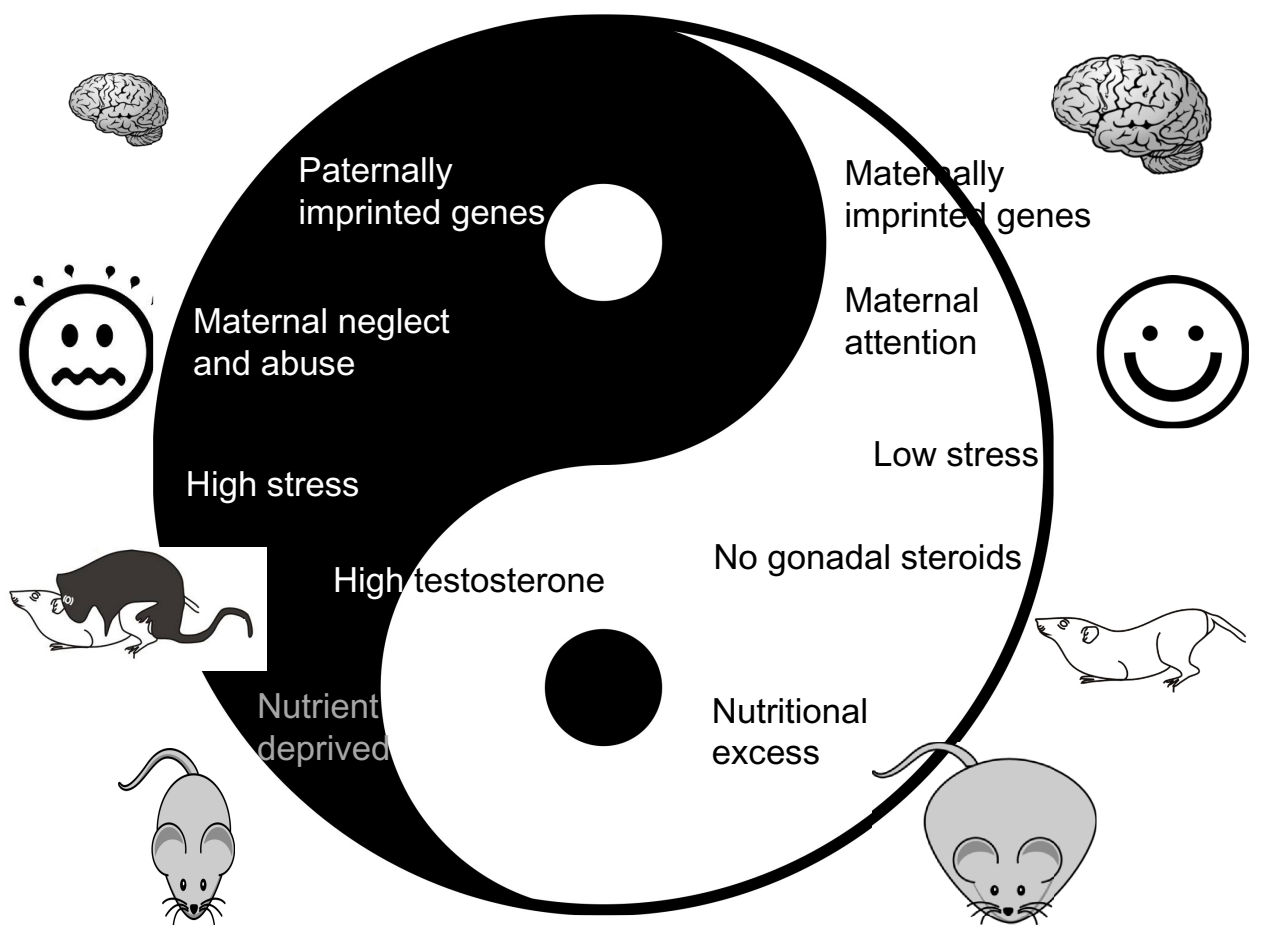

Figure $\mathbf{2}$ The yin and yang of epigenetics and brain development.

Notes: Many environmental and intrinsic factors regulate epigenetic modification and exert enduring effects on the brain and body, which can be both positive and negative. For instance, imprinting is a form of epigenetic regulation involving parent of origin allelic expression and in some cases paternally imprinted genes select for smaller brain size compared to maternally imprinted genes which favor brain growth. Early-life abuse, which is mostly from the mother in our animal models, can permanently change adult behavior by altering anxiety levels and stress responding. Gonadal hormones organize the developing brain, with testosterone from the male testis directing the process of masculinization leading to adult male sexual behavior, whereas in developing females there are low levels of steroids and the brain is feminized as a result. Nutrients experienced in utero may alter epigenetic marks to prepare the developing fetus for a future life of plenty or deprivation by programming metabolic and feeding pathways. 
on primate brain development by decreasing cell proliferation, increasing cell death, and slowing neuronal maturation, without reducing fetal brain or body weight and having only a marginal impact on maternal weight. ${ }^{100}$ Like maternal high-fat diets, maternal caloric restriction can result in sexspecific effects on offspring. ${ }^{101,102}$ Interestingly, rodent models of malnutrition during pregnancy often produce similar phenotypes in offspring as maternal high-fat models, where offspring display glucose intolerance and obesity. ${ }^{103}$ Similar to overconsumption models, the transgenerational impact of malnutrition is also passed along the paternal germline through alterations in DNA methylation. ${ }^{104,105}$

Deficiencies in additional nutritional requirements, such as iodine, during pregnancy can also lead to neurodevelopmental insults. Iodine deficiencies commonly cause hypothyroidism resulting in low maternal thyroxine during early pregnancy, a period during which the fetus relies on maternal sources of thyroid hormones. Low maternal thyroxine is well known to cause fetal brain damage, in severe cases resulting in mental retardation and cerebral palsy. Experimentally-induced iodine deficiency and hypothyroidism results in altered cellular migration, gliogenesis, and cytoarchitecture in the developing cortex and hippocampus. ${ }^{106,107}$ Genes important for neural development such as brain-derived neurotrophic factor (BDNF) and reelin, which controls cellular migration and interactions, are regulated by thyroid hormones developmentally. ${ }^{108,109}$ Methylation of BDNF and reelin is increased in the hippocampus of the offspring of hypothyroid rats and acetylation is decreased at the promoters of these genes, ${ }^{110}$ once again suggesting that in utero hormones can have long-term impacts on brain development via epigenetic mechanisms.

\section{Additional thoughts}

Epigenetic modifications to the developing brain are a double-edged sword. On the one hand, the brain's developmental trajectory is modified in anticipation of the future environment, thereby maximizing adaptability and possibly resilience in the face of challenging circumstances. On the other hand, the predictability of the future environment is not precise, and a mature individual may be burdened by an epigenetic profile that is no longer optimal for the current conditions. This can cut both ways, circumstances may now be challenging in comparison to an idyllic development, leaving the individual unprepared, or conversely, the threats that previously existed may now be gone but the individual remains hypervigilant, easily stressed, and/or metabolically preparing for starvation in the face of ample nutrients. The good news is that epigenetic modifications are not permanent, at least not in the brain. Indeed they are far more labile than originally believed possible. This means that as adults an individual can continue to adapt to their immediate environment, or perhaps remove and modify previously suboptimal epigenetic modifications. But how, when and why this is achieved remain open questions.

Unlocking the secrets of the epigenome has the potential to enormously impact human health and disease. Adverse conditions that may inadvertently hamper an individual's future well-being may have occurred in utero or shortly after birth, a time distantly removed from the present circumstance and one certainly out of the individual's control. Sometimes, simply knowing that early-life adversity impacts adult health and well-being by altering the epigenome aids an individual in developing coping strategies. Ultimately, however, we would like to provide therapeutic and behavioral strategies that erase or reverse deleterious epigenetic programming, and perhaps even provide a new healthier profile. Just as we encourage healthy eating to maintain an appropriate body weight, healthy thinking may also improve brain functioning. But disordered thinking cannot be simply wished away. Mental health disorders such as depression, obsessive-compulsive disorder, posttraumatic stress disorder and so on, are organic phenomenon with biological origins. A combination of pharmacological and behavioral therapies is emerging as the most effective treatments for long-term modifications. This is also true in areas of weight control where bariatric surgery is most successful when combined with behavioral modification. One can speculate this is because the combination of approaches maximizes epigenetic profile changes, although this remains to be seen. Regardless, the challenge is to adapt our health care system to recognizing the totality of treatment and its enduring consequences, which includes changes at the level of the genome.

\section{Summary}

This review has attempted to provide a comprehensive and up-to-date discussion of our current understanding of epigenetic control of brain development in the context of hormonal and nutritional influences. However, like the early stages of a Seurat painting, our picture consists mostly of individual points with no coherent image. The brain is a collection of diverse but interconnected regions each made of diverse but interconnected cell types. None of the current techniques used to interrogate epigenetic changes in the developing brain have considered cell diversity as a variable, 
and many more brain regions are left unexplored than have been currently examined. Moreover, there is no coordinated attack on histone and DNA modifications within one brain region, cell type or even behavioral response. Instead we have individual investigators exploring their own particular system in isolation. But this is often the case during the early days of a new (old, but newly rejuvenated) field. With additional studies, new technologies and an improved sophistication in our understanding of the dynamics of epigenetics in the brain over all, we will add more and more points to the canvas and eventually, hopefully soon, a clear and pleasing picture explaining how epigenetics establishes and maintains early-life programming of the brain, will emerge.

\section{Disclosure}

The authors report no conflicts of interest in this work.

\section{References}

1. Waddington $\mathrm{CH}$. Canalization of development and the inheritance of acquired characters. Nature. 1942;150(3811):563-565.

2. Lister R, Mukamel EA, Nery JR, et al. Global epigenomic reconfiguration during mammalian brain development. Science. 2013;341(6146): 1237905

3. Ramsahoye BH, Biniszkiewicz D, Lyko F, Clark V, Bird AP, Jaenisch R. Non-CpG methylation is prevalent in embryonic stem cells and may be mediated by DNA methyltransferase 3a. Proc Natl Acad Sci U S A. 2000;97(10):5237-5242.

4. Stadler MB, Murr R, Burger L, et al. DNA-binding factors shape the mouse methylome at distal regulatory regions. Nature. 2011;480(7378): 490-495.

5. Goll MG, Bestor TH. Eukaryotic cytosine methyltransferases. Annu Rev Biochem. 2005;74:481-514.

6. Harrington MA, Jones PA, Imagawa M, Karin M. Cytosine methylation does not affect binding of transcription factor Sp1. Proc Natl Acad Sci US A. 1988;85(7):2066-2070.

7. Pieper RO, Patel S, Ting SA, Futscher BW, Costello JF. Methylation of $\mathrm{CpG}$ island transcription factor binding sites is unnecessary for aberrant silencing of the human MGMT gene. J Biol Chem. 1996; 271(23):13916-13924.

8. Wölfl S, Schräder M, Wittig B. Lack of correlation between DNA methylation and transcriptional inactivation: the chicken lysozyme gene. Proc Natl Acad Sci U S A. 1991;88(1):271-275.

9. Schwarz JM, Nugent BM, McCarthy MM. Developmental and hormone-induced epigenetic changes to estrogen and progesterone receptor genes in brain are dynamic across the life span. Endocrinology. 2010;151(10):4871-4881.

10. Hon GC, Rajagopal N, Shen Y, et al. Epigenetic memory at embryonic enhancers identified in DNA methylation maps from adult mouse tissues. Nat Genet. 2013;45(10):1198-1206.

11. Shukla S, Kavak E, Gregory M, et al. CTCF-promoted RNA polymerase II pausing links DNA methylation to splicing. Nature. 2011;479(7371):74-79.

12. Maunakea AK, Nagarajan RP, Bilenky M, et al. Conserved role of intragenic DNA methylation in regulating alternative promoters. Nature. 2010;466(7303):253-257.

13. Okano M, Bell DW, Haber DA, Li E. DNA methyltransferases Dnmt3a and Dnmt3b are essential for de novo methylation and mammalian development. Cell. 1999;99(3):247-257.
14. Suetake I, Shinozaki F, Miyagawa J, Takeshima H, Tajima S. DNMT3L stimulates the DNA methylation activity of Dnmt3a and Dnmt3b through a direct interaction. J Biol Chem. 2004;279(26):27816-27823.

15. Jeltsch A, Jurkowska RZ. New concepts in DNA methylation. Trends Biochem Sci. 2014;39(7):310-318.

16. Fatemi M, Hermann A, Gowher H, Jeltsch A. Dnmt3a and Dnmt1 functionally cooperate during de novo methylation of DNA. Eur $J$ Biochem. 2002;269(20):4981-4984.

17. Kim GD, Ni J, Kelesoglu N, Roberts RJ, Pradhan S. Co-operation and communication between the human maintenance and de novo DNA (cytosine-5) methyltransferases. EMBO J. 2002;21(15):4183-4195.

18. Liang G, Chan MF, Tomigahara Y, et al. Cooperativity between DNA methyltransferases in the maintenance methylation of repetitive elements. Mol Cell Biol. 2002;22(2):480-491.

19. Chen T, Ueda Y, Dodge JE, Wang Z, Li E. Establishment and maintenance of genomic methylation patterns in mouse embryonic stem cells by Dnmt3a and Dnmt3b. Mol Cell Biol. 2003;23(16):5594-5605.

20. Arand J, Spieler D, Karius T, et al. In Vivo Control of CpG and nonCpG DNA methylation by DNA methyltransferases. PLoS Genet. 2012;8(6):e1002750.

21. Defossez P-A. Ceci n'est pas une DNMT: Recently discovered functions of DNMT2 and their relation to methyltransferase activity (Comment on DOI 10.1002/bies.201300088). BioEssays. 2013;35(12): 1024-1024.

22. Goll MG, Kirpekar F, Maggert KA, et al. Methylation of tRNAAsp by the DNA methyltransferase Homolog Dnmt2. Science. 2006; 311(5759):395-398.

23. Raddatz G, Guzzardo PM, Olova N, et al. Dnmt2-dependent methylomes lack defined DNA methylation patterns. Proc Natil Acad Sci U S A. 2013;110(21):8627-8631.

24. Wu SC, Zhang Y. Active DNA demethylation: many roads lead to Rome. Nat Rev Mol Cell Biol. 2010;11(9):607-620.

25. Pastor WA, Aravind L, Rao A. TETonic shift: biological roles of TET proteins in DNA demethylation and transcription. Nat Rev Mol Cell Biol. 2013;14(6):341-356.

26. Meissner A, Mikkelsen TS, Gu H, et al. Genome-scale DNA methylation maps of pluripotent and differentiated cells. Nature. 2008;454(7205):766-770.

27. Liang P, Song F, Ghosh S, et al. Genome-wide survey reveals dynamic widespread tissue-specific changes in DNA methylation during development. BMC Genomics. 2011;12(1):231.

28. Jenuwein T, Allis CD. Translating the histone code. Science. 2001; 293(5532):1074-1080.

29. Utley RT, Ikeda K, Grant PA, et al. Transcriptional activators direct histone acetyltransferase complexes to nucleosomes. Nature. 1998;394(6692):498-502.

30. Narlikar GJ, Fan H-Y, Kingston RE. Cooperation between complexes that regulate chromatin structure and transcription. Cell. 2002; 108(4):475-487.

31. Rayman JB, Takahashi Y, Indjeian VB, et al. E2F mediates cell cycle-dependent transcriptional repression in vivo by recruitment of an HDAC $1 / \mathrm{mSin} 3 \mathrm{~B}$ corepressor complex. Genes Dev. 2002; 16(8):933-947.

32. Hsieh J, Nakashima K, Kuwabara T, Mejia E, Gage FH. Histone deacetylase inhibition-mediated neuronal differentiation of multipotent adult neural progenitor cells. Proc Natl Acad Sci U S A. 2004;101(47):16659-16664.

33. Balasubramaniyan V, Boddeke E, Bakels R, et al. Effects of histone deacetylation inhibition on neuronal differentiation of embryonic mouse neural stem cells. Neuroscience. 2006;143(4):939-951.

34. Montgomery RL, Hsieh J, Barbosa AC, Richardson JA, Olson EN. Histone deacetylases 1 and 2 control the progression of neural precursors to neurons during brain development. Proc Natl Acad Sci U S A. 2009;106(19):7876-7881.

35. Schoeftner S, Sengupta AK, Kubicek S, et al. Recruitment of PRC1 function at the initiation of $\mathrm{X}$ inactivation independent of PRC2 and silencing. EMBO J. 2006;25(13):3110-3122. 
36. Jepsen K, Solum D, Zhou T, et al. SMRT-mediated repression of an $\mathrm{H} 3 \mathrm{~K} 27$ demethylase in progression from neural stem cell to neuron. Nature. 2007:450(7168):415-419.

37. Tsukada Y-i, Ishitani T, Nakayama KI. KDM7 is a dual demethylase for histone H3 Lys 9 and Lys 27 and functions in brain development. Genes Dev. 2010;24(5):432-437.

38. Lee JT. Epigenetic regulation by long noncoding RNAs. Science. 2012;338(6113):1435-1439.

39. Lee Y, Kim M, Han J, et al. MicroRNA genes are transcribed by RNA polymerase II. EMBO J. 2004;23(20):4051-4060.

40. Han J, Lee Y, Yeom K-H, et al. Molecular basis for the recognition of primary microRNAs by the Drosha-DGCR8 complex. Cell. 2006; 125(5):887-901.

41. Bohnsack MT, Czaplinski K, Görlich D. Exportin 5 is a RanGTPdependent dsRNA-binding protein that mediates nuclear export of pre-miRNAs. RNA. 2004;10(2):185-191.

42. Hutvágner G, McLachlan J, Pasquinelli AE, Bálint É, Tuschl T, Zamore PD. A cellular function for the RNA-interference enzyme Dicer in the maturation of the let-7 small temporal RNA. Science. 2001; 293(5531):834-838.

43. Krichevsky AM, King KS, Donahue CP, Khrapko K, Kosik KS. A microRNA array reveals extensive regulation of microRNAs during brain development. RNA. 2003;9(10):1274-1281.

44. Filipowicz W, Bhattacharyya SN, Sonenberg N. Mechanisms of posttranscriptional regulation by microRNAs: are the answers in sight? Nat Rev Genet. 2008;9(2):102-114.

45. Fatica A, Bozzoni I. Long non-coding RNAs: new players in cell differentiation and development. Nat Rev Genet. 2014;15(1):7-21.

46. Batista PJ, Chang HY. Long noncoding RNAs: cellular address codes in development and disease. Cell. 2013;152(6):1298-1307.

47. Rinn JL, Chang HY. Genome regulation by long noncoding RNAs. Annu Rev Biochem. 2012;81:145-166.

48. Guttman M, Rinn JL. Modular regulatory principles of large non-coding RNAs. Nature. 2012;482(7385):339-346.

49. Ng SY, Johnson R, Stanton LW. Human long non-coding RNAs promote pluripotency and neuronal differentiation by association with chromatin modifiers and transcription factors. EMBO J. 2012;31(3):522-533.

50. Mercer TR, Dinger ME, Sunkin SM, Mehler MF, Mattick JS. Specific expression of long noncoding RNAs in the mouse brain. Proc Natl Acad Sci U SA. 2008;105(2):716-721.

51. Pauli A, Valen E, Lin MF, et al. Systematic identification of long noncoding RNAs expressed during zebrafish embryogenesis. Genome Res. 2012;22(3):577-591.

52. Zhao J, Sun BK, Erwin JA, Song J-J, Lee JT. Polycomb proteins targeted by a short repeat RNA to the mouse X chromosome. Science. 2008; 322(5902): 750-756

53. Nagano T, Mitchell JA, Sanz LA, et al. The Air noncoding RNA epigenetically silences transcription by targeting G9a to chromatin. Science. 2008;322(5908):1717-1720.

54. Khalil AM, Guttman M, Huarte M, et al. Many human large intergenic noncoding RNAs associate with chromatin-modifying complexes and affect gene expression. Proc Natl Acad Sci U S A. 2009;106(28): 11667-11672.

55. Ørom UA, Derrien T, Beringer M, et al. Long noncoding RNAs with enhancer-like function in human cells. Cell. 2010;143(1):46-58.

56. Wang KC, Yang YW, Liu B, et al. A long noncoding RNA maintains active chromatin to coordinate homeotic gene expression. Nature. 2011; 472(7341):120-124.

57. Li W, Notani D, Ma Q, et al. Functional roles of enhancer RNAs for oestrogen-dependent transcriptional activation. Nature. 2013; 498(7455):516-520

58. Davies W, Isles AR, Wilkinson LS. Imprinted gene expression in the brain. Neurosci Biobehav Rev. 2005;29(3):421-430.

59. Lee JT, Bartolomei MS. X-inactivation, imprinting, and long noncoding RNAs in health and disease. Cell. 2013;152(6):1308-1323.

60. Keverne EB, Fundele R, Narasimha M, Barton SC, Surani MA. Genomic imprinting and the differential roles of parental genomes in brain development. Dev Brain Res. 1996;92(1):91-100.
61. Barton SC, Ferguson-Smith AC, Fundele R, Surani MA. Influence of paternally imprinted genes on development. Development. 1991; 113(2):679-687.

62. Cattanach B, Kirk M. Differential activity of maternally and paternally derived chromosome regions in mice. Landmarks in Medical Genetics: Classic Papers with Commentaries. New York, NY: Oxford University Press; 2004;51:245.

63. Renata Z, Nerina G, Noa M-L, et al. Ras-GRF, the activator of Ras, is expressed preferentially in mature neurons of the central nervous system. Mol Brain Res. 1997;48(1):140-144.

64. Yamasaki K, Joh K, Ohta T, et al. Neurons but not glial cells show reciprocal imprinting of sense and antisense transcripts of Ube3a. Hum Mol Genet. 2003;12(8):837-847.

65. Yamasaki Y, Kayashima T, Soejima H, et al. Neuron-specific relaxation of Igf2r imprinting is associated with neuron-specific histone modifications and lack of its antisense transcript Air. Hum Mol Genet. 2005;14(17):2511-2520.

66. Nugent BM, McCarthy MM. Epigenetic underpinnings of developmental sex differences in the brain. Neuroendocrinology. 2011; 93(3):150-158.

67. Amateau SK, McCarthy MM. A novel mechanism of dendritic spine plasticity involving estradiol induction of prostaglandin-E2.J Neurosci. 2002;22(19):8586-8596.

68. Wright CL, McCarthy MM. Prostaglandin E2-induced masculinization of brain and behavior requires protein kinase A, AMPA/kainate, and metabotropic glutamate receptor signaling. J Neurosci. 2009; 29(42):13274-13282.

69. Mong JA, Glaser E, McCarthy MM. Gonadal steroids promote glial differentiation and alter neuronal morphology in the developing hypothalamus in a regionally specific manner. Jf Neurosci. 1999; 19(4):1464-1472.

70. Lenz KM, Nugent BM, McCarthy MM. Sexual differentiation of the rodent brain: dogma and beyond. Front Neurosci. 2012;6:26.

71. Arnold AP. The organizational-activational hypothesis as the foundation for a unified theory of sexual differentiation of all mammalian tissues. Horm Behav. 2009;55(5):570-578.

72. Lenz KM, McCarthy MM. A starring role for microglia in brain sex differences. Neuroscientist. Epub May 28, 2014.

73. McCarthy MM, Auger AP, Bale TL, et al. The epigenetics of sex differences in the brain. J Neurosci. 2009;29(41):12815-12823.

74. Tsai H-W, Grant PA, Rissman EF. Sex differences in histone modifications in the neonatal mouse brain. Epigenetics. 2009;4(1): 47-53.

75. Shen EY, Ahern TH, Cheung I, et al. Epigenetics and sex differences in the brain: a genome-wide comparison of Histone-3 Lysine-4 Trimethylation (H3K4me3) in male and female mice. Exp Neurol. 2014. pii: S0014-4886(14)00258-1. doi: 10.1016/j.expneurol.2014.08.006.

76. Murray EK, Hien A, de Vries GJ, Forger NG. Epigenetic control of sexual differentiation of the bed nucleus of the stria terminalis. Endocrinology. 2009;150(9):4241-4247.

77. Matsuda KI, Mori H, Nugent BM, Pfaff DW, McCarthy MM, Kawata M. Histone deacetylation during brain development is essential for permanent masculinization of sexual behavior. Endocrinology. 2011; 152(7):2760-2767.

78. Ghahramani NM, Ngun TC, Chen P-Y, et al. The effects of perinatal testosterone exposure on the DNA methylome of the mouse brain are late-emerging. Biol Sex Differ. 2014;5(1):8.

79. Morgan CP, Bale TL. Sex differences in microRNA regulation of gene expression: no smoke, just miRs. Biol Sex Differ. 2012;3(1):22.

80. Morgan CP, Bale TL. Early prenatal stress epigenetically programs dysmasculinization in second-generation offspring via the paternal lineage. J Neurosci. 2011;31(33):11748-11755.

81. Francis D, Diorio J, Liu D, Meaney MJ. Nongenomic transmission across generations of maternal behavior and stress responses in the rat. Science. 1999;286(5442):1155-1158.

82. Liu D, Diorio J, Tannenbaum B, et al. Maternal care, hippocampal glucocorticoid receptors, and hypothalamic-pituitary-adrenal responses to stress. Science. 1997;277(5332):1659-1662. 
83. Weaver IC, Cervoni N, Champagne FA, et al. Epigenetic programming by maternal behavior. Nat Neurosci. 2004;7(8):847-854.

84. McGowan PO, Sasaki A, D'Alessio AC, et al. Epigenetic regulation of the glucocorticoid receptor in human brain associates with childhood abuse. Nat Neurosci. 2009;12(3):342-348.

85. Mueller BR, Bale TL. Sex-specific programming of offspring emotionality after stress early in pregnancy. $J$ Neurosci. 2008;28(36): 9055-9065.

86. Rodgers AB, Morgan CP, Bronson SL, Revello S, Bale TL. Paternal stress exposure alters sperm microRNA content and reprograms offspring HPA stress axis regulation. J Neurosci. 2013;33(21): 9003-9012.

87. Dias BG, Ressler KJ. Parental olfactory experience influences behavior and neural structure in subsequent generations. Nat Neurosci. 2014; 17(1):89-96.

88. Landrigan PJ, Sonawane B, Butler RN, Trasande L, Callan R, Droller D. Early environmental origins of neurodegenerative disease in later life. Environ Health Perspect. 2005;113(9):1230-1233.

89. Hales CN, Barker DJ. Type 2 (non-insulin-dependent) diabetes mellitus: the thrifty phenotype hypothesis. Diabetologia. 1992;35(7):595-601.

90. Ogden CL, Carroll MD, Kit BK, Flegal KM. PRevalence of childhood and adult obesity in the united states, 2011-2012. JAMA. 2014;311(8):806-814.

91. Guo F, Jen K-LC. High-fat feeding during pregnancy and lactation affects offspring metabolism in rats. Physiol Behav. 1995;57(4): 681-686.

92. Elahi MM, Cagampang FR, Mukhtar D, Anthony FW, Ohri SK, Hanson MA. Long-term maternal high-fat feeding from weaning through pregnancy and lactation predisposes offspring to hypertension, raised plasma lipids and fatty liver in mice. Br J Nutr. 2009;102(04): 514-519.

93. Khan IY, Dekou V, Douglas G, et al. A high-fat diet during rat pregnancy or suckling induces cardiovascular dysfunction in adult offspring. $\mathrm{Am}$ J Physiol Regul Integr Comp Physiol. 2005;288(1):R127-R133.

94. Rooney K, Ozanne S. Maternal over-nutrition and offspring obesity predisposition: targets for preventative interventions. Int $J$ Obes. 2011;35(7):883-890.

95. Samuelsson A-M, Matthews PA, Argenton M, et al. Diet-induced obesity in female mice leads to offspring hyperphagia, adiposity, hypertension, and insulin resistance: a novel murine model of developmental programming. Hypertension. 2008;51(2):383-392.

96. Dunn GA, Bale TL. Maternal high-fat diet promotes body length increases and insulin insensitivity in second-generation mice. Endocrinology. 2009;150(11):4999-5009.

97. Dunn GA, Bale TL. Maternal high-fat diet effects on third-generation female body size via the paternal lineage. Endocrinology. 2011;152(6): 2228-2236.
98. Waterland R, Travisano M, Tahiliani K, Rached M, Mirza S. Methyl donor supplementation prevents transgenerational amplification of obesity. Int J Obes. 2008;32(9):1373-1379.

99. Vucetic Z, Kimmel J, Totoki K, Hollenbeck E, Reyes TM. Maternal high-fat diet alters methylation and gene expression of dopamine and opioid-related genes. Endocrinology. 2010;151(10):4756-4764.

100. Antonow-Schlorke I, Schwab M, Cox LA, et al. Vulnerability of the fetal primate brain to moderate reduction in maternal global nutrient availability. Proc Natl Acad Sci U S A. 2011;108(7):3011-3016.

101. Thamotharan M, Garg M, Oak S, et al. Transgenerational inheritance of the insulin-resistant phenotype in embryo-transferred intrauterine growth-restricted adult female rat offspring. Am J Physiol Endocrinol Metab. 2007;292(5):E1270-E1279.

102. Pinheiro A, Salvucci I, Aguila M, Mandarim-de-Lacerda C. Protein restriction during gestation and/or lactation causes adverse transgenerational effects on biometry and glucose metabolism in F1 and F2 progenies of rats. Clin Sci. 2008;114:381-392.

103. Jimenez-Chillaron JC, Isganaitis E, Charalambous M, et al. Intergenerational transmission of glucose intolerance and obesity by in utero undernutrition in mice. Diabetes. 2009;58(2):460-468.

104. Radford EJ, Ito M, Shi H, et al. In utero undernourishment perturbs the adult sperm methylome and intergenerational metabolism. Science. 2014;345(6198): 1255903.

105. Martínez D, Pentinat T, Ribó S, et al. In utero undernutrition in male mice programs liver lipid metabolism in the second-generation offspring involving altered Lxra DNA methylation. Cell Metab. 2014;19(6):941-951.

106. Martínez-Galán JR, Pedraza P, Santacana M, Del Ray FE, De Escobar GM, Ruiz-Marcos A. Early effects of iodine deficiency on radial glial cells of the hippocampus of the rat fetus. A model of neurological cretinism. J Clin Invest. 1997;99(11):2701.

107. Lavado-Autric R, Ausó E, García-Velasco JV, et al. Early maternal hypothyroxinemia alters histogenesis and cerebral cortex cytoarchitecture of the progeny. J Clin Invest. 2003;111(7):1073-1082.

108. Oppenheimer JH, Schwartz HL. Molecular basis of thyroid hormonedependent brain development 1. Endocr Rev. 1997;18(4):462-475.

109. Bernal J, Guadaño-Ferraz A. Analysis of thyroid hormone-dependent genes in the brain by in situ hybridization. Thyroid Hormone Receptors. New York, NY: Springer Science+Business Media; 2002:71-90.

110. Sui L, Li B-M. Effects of perinatal hypothyroidism on regulation of reelin and brain-derived neurotrophic factor gene expression in rat hippocampus: role of DNA methylation and histone acetylation. Steroids. 2010;75(12):988-997.
Advances in Genomics and Genetics

\section{Publish your work in this journal}

Advances in Genomics and Genetics is an international, peer reviewed, open access journal that focuses on new developments in characterizing the human and animal genome and specific gene expressions in health and disease. Particular emphasis will be given to those studies that elucidate genes, biomarkers and targets in the development of new or improved therapeutic

\section{Dovepress}

interventions. The journal is characterized by the rapid reporting of reviews, original research, methodologies, technologies and analytics in this subject area. The manuscript management system is completely online and includes a very quick and fair peer-review system. Visit http://www.dovepress.com/ testimonials.php to read real quotes from published authors. 